\title{
Efficacy and safety of plerixafor for hematopoietic stem cell mobilization for autologous transplantation in patients with non-Hodgkin lymphoma and multiple myeloma: A systematic review and meta-analysis
}

\author{
XIAOYANG YANG ${ }^{1}$, MENGJIE WAN $^{1}$, FENG YU $^{1}$ and ZHIDONG WANG ${ }^{2}$ \\ ${ }^{1}$ Department of Hematology, Affiliated Haikou Hospital of Xiangya Medical College, \\ Central South University and Haikou Municipal People's Hospital, Haikou, Hainan 570208; \\ ${ }^{2}$ Department of Hematology, People's Hospital of Peking University, Beijing 100044, P.R. China
}

Received May 10, 2019; Accepted June 17, 2019

DOI: $10.3892 / \mathrm{etm} .2019 .7691$

\begin{abstract}
Plerixafor in combination granulocyte-colony stimulating factor (G-CSF) has been used for the mobilization of hematopoietic stem cells (HSCs) to the peripheral blood for collection and subsequent autologous transplantation in patients with non-Hodgkin lymphoma (NHL) and multiple myeloma (MM). The aim of this study was to systematically search the published literature and analyze evidence on the efficacy of additional plerixafor for successful HSC mobilization in patients with NHL and MM, and to evaluate the safety of the drug. The PubMed, Scopus, Cochrane Central Register of Controlled Trials (CENTRAL) and Google scholar databases were searched electronically for studies published in the English language up to March, 2019. Five studies ( 3 on NHL and 2 on MM) were included in this review article. The meta-analysis of data of 364 patients in the treatment group and 368 patients in the control group, indicated that the mobilization of $\geq 5 / 6 \times 10^{6} \mathrm{CD} 34^{+}$cells $/ \mathrm{kg}$ in 4 or less apheresis days was superior with plerixafor $+\mathrm{G}-\mathrm{CSF}$ than with G-CSF alone (RR=2.59, 95\% CI: 1.40 to 4.81; $\mathrm{P}<0.0001)$. Similarly, a greater proportion of patients in the treatment group exhibited the mobilization of $\geq 2 \times 10^{6} \mathrm{CD} 34^{+}$cells $/ \mathrm{kg}$ in 4 or less apheresis days ( $\mathrm{RR}=1.46,95 \% \mathrm{CI}: 1.01$ to $2.12 ; \mathrm{P}=0.04)$. The addition of plerixafor significantly increased the total collection of $\mathrm{CD}_{3} 4^{+}$cells (random: $\mathrm{MD}=4.21 ; 95 \% \mathrm{CI}$ : 2.85 to 5.57 ; $\mathrm{P}<0.00001)$. Meta-analysis indicated no significant increase in adverse events with the addition of plerixafor for HSC mobilization $(\mathrm{RR}=1.03,95 \% \mathrm{CI}$ : 0.99 to $1.06 ; \mathrm{P}=0.16)$. On the whole, the findings of this study indicate that the addition of plerixafor to
\end{abstract}

Correspondence to: Dr Xiaoyang Yang, Department of Hematology, Affiliated Haikou Hospital of Xiangya Medical College, Central South University and Haikou Municipal People's Hospital, 43 People's Avenue, Meilan, Haikou, Hainan 570208, P.R. China

E-mail: y108108@126.com

Key words: hematopoietic stem cell, plerixafor, lymphoma, multiple myeloma
G-CSF leads to an increased HSC collection in a shorter period of time with no concomitant increase in adverse events. Further randomized controlled trials with a larger sample size evaluating short term efficacy, as well as long term survival would help to further strengthen the evidence on this subject.

\section{Introduction}

High-dose chemotherapy along with autologous hematopoietic stem cell transplantation (HSCT) is a widely used effective therapeutic option for patients with non-Hodgkin lymphoma (NHL) and multiple myeloma (MM). HSCT has greatly evolved from its early days where the only source for the harvesting of hematopoietic stem cells (HSCs) was the bone marrow. A paradigm shift in HSC collection has been made possible with the use of granulocyte-colony stimulating factor (G-CSF) to increase the number of circulating $\mathrm{CD} 34^{+}$cells and improvements in collection devices, which allows for HSC collection in fewer apheresis sessions $(1,2)$.

Successful HSCT is largely dependent on the adequate collection of $\mathrm{CD}_{3} 4^{+}$cells. The American Society for Blood and Marrow Transplantation recommends $4-5 \times 10^{6} \mathrm{CD} 34^{+}$cells $/ \mathrm{kg}$ as the optimal number and $\geq 2 \times 10^{6} \mathrm{CD} 34^{+}$cells $/ \mathrm{kg}$ as the minimum number of HSCs to support transplantation (3). A large number of cases, however, are hard-to-mobilize or require multiple mobilization attempts for successful HSCT. The number of patients who are 'difficult mobilizers' varies considerably, with an incidence ranging from 5 to $10 \%$ to approximately $30 \%(2,4,5)$. In general, greater mobilization issues have been found in patients with NHL compared to those suffering from MM (5).

Plerixafor, a novel bicyclam small-molecule, was initially developed for managing HIV infections. It reversibly binds to chemokine receptor CXCR4 and antagonizes the chemokine stromal cell-derived factor- $1 \alpha$ (SDF-1 $\alpha)$ interaction, thereby inducing the mobilization of stem cells into the bloodstream from the bone marrow $(6,7)$. It has been approved in the US and EU for the collection of HSCs and autologous transplantation in patients with NHL and MM, when used in combination with G-CSF (8). A number of literature reviews describing the role of plerixafor 
in HSC mobilization have been published $(2,9,10)$. However, to date, and at least to the best of our knowledge, level-1 evidence in the form of a systematic review and meta-analysis has been conducted only once (11). The published review analyses data from the first 2 randomized controlled trials (RCTs) were conducted by DiPersio et al in 2009 (12,13). With the addition of new studies $(14,15)$ from different centers on the efficacy of plerixafor for HSCT, there is a need for an updated meta-analysis. Therefore, the aim of this study was to systematically search the published literature and analyze evidence on the efficacy of additional plerixafor for successful HSC mobilization in patients with NHL and MM, and to evaluate the safety of the drug.

\section{Data and methods}

This systematic review of the literature was conducted in line with the Preferred Reporting Items for Systematic Reviews and Meta-analyses (PRISMA) statement (16) and guidelines of the Cochrane Handbook for Systematic Reviews of Intervention (17).

Eligibility criteria. We included studies conducted on patients with NHL or MM, in first or second complete or partial remission, who were eligible for autologous HSCT and had not undergone any prior failed mobilization or HSCT. Study intervention was the use of additional plerixafor for HSC mobilization compared to placebo or no additional therapy. The outcome of the trial was to report the number of patients achieving optimal HSC mobilization, the time required to achieve optimal HSC mobilization and adverse events. Non-English language studies, studies on healthy volunteers, uncontrolled and non-randomized studies were excluded.

Search strategy. We searched the PubMed, Scopus, Cochrane Central Register of Controlled Trials (CENTRAL) and Google scholar databases (first 100 results) electronically for articles published up to March, 2019. The key words used in various combinations were as follows: Lymphoma [MeSH], multiple myeloma [MeSH], non-Hodgkin lymphoma [MeSH], plerixafor [MeSH], plerixafor hydrochloride [MeSH], granulocyte-colony stimulating factor $[\mathrm{MeSH}]$, filgrastim $[\mathrm{MeSH}]$, placebo effect [MeSH], adult stem cells [MeSH], hematopoietic stem cell [MeSH], hematopoietic stem cell mobilization [MeSH] and CD $34^{+}$cells [Free text]. Study designs searched were RCTs. Studies not utilizing a placebo drug in the control group were also included. Previous meta-analyses and review articles were analyzed for the identification of any additional studies.

Data collection and analysis. Potentially eligible studies were evaluated separately by two reviewers based on the inclusion and exclusion criteria. Following the removal of duplicates, studies were scrutinized by their titles and abstracts. The full-texts of selected articles were then scanned for inclusion in the review. Any difference in opinion was resolved by discussion. We extracted the following data from the included trials: Authors, publication year, inclusion/exclusion criteria, sample size, demographic data, plerixafor and G-CSF protocol, apheresis protocol, outcomes assessed and adverse events. The primary objective was to perform the quantitative analysis of successful optimal HSC mobilization. The secondary objec-

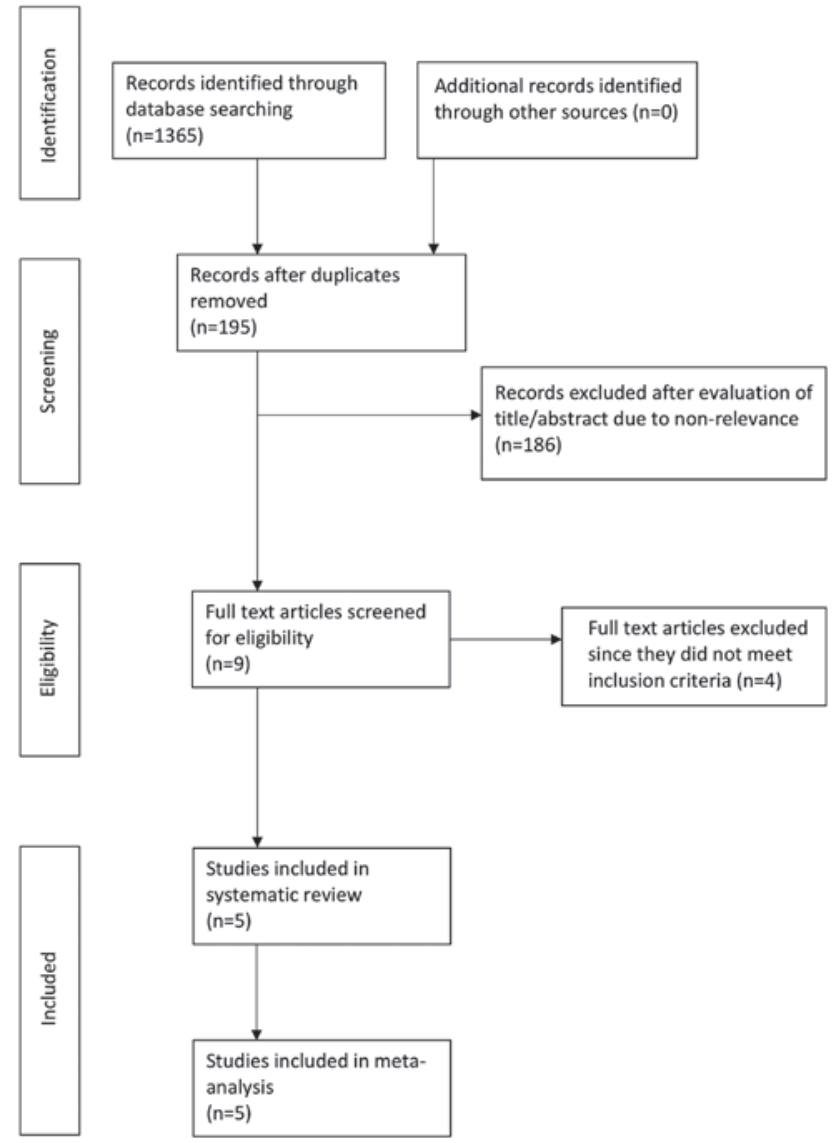

Figure 1. Flow chart of this study.

tives were the following: The analysis of number of patients achieving minimal HSC mobilization, the quantitative analysis of the time required to achieve optimal and minimal HSC mobilization, the number of $\mathrm{CD} 34^{+}$cells collected, the number of patients subsequently transplanted and adverse events.

Risk of bias in individual studies. We assessed the risk of bias in each trial using the Cochrane Collaboration risk assessment tool for RCTs (18). Seven criteria were evaluated for each study: Random sequence generation, allocation concealment, blinding of participants and personnel, blinding of outcome assessment, incomplete outcome data, selective outcome reporting and other biases. Studies were scored for each criteria as follows: Low risk (score of 2), high risk (score of 0 ), or unclear risk of bias (score of 1). Based on the scores awarded, individual studies were grouped as low-(score 0-5), medium-(score 6-10), or high-(score 11-14) quality trials.

Statistical analysis. Meta-analysis was carried out only if at least 3 trials reported data on the same scale. The outcome data extracted was entered into Review Manager [RevMan, version 5.3; Nordic Cochrane Centre (Cochrane Collaboration)], Copenhagen, Denmark; 2014) for quantitative analysis. We used Intention to treat data from the trials for the purpose of analysis. Considering the heterogeneity amongst studies, a random-effects model was used to calculate the pooled effect size. Heterogeneity was calculated using the $\mathrm{I}^{2}$ statistic. $\mathrm{I}^{2}$ values of $25-50 \%$ represented as low, values of $50-75 \%$ as medium and $>75 \%$ were represented as substantial heterogeneity. For binary outcomes, 


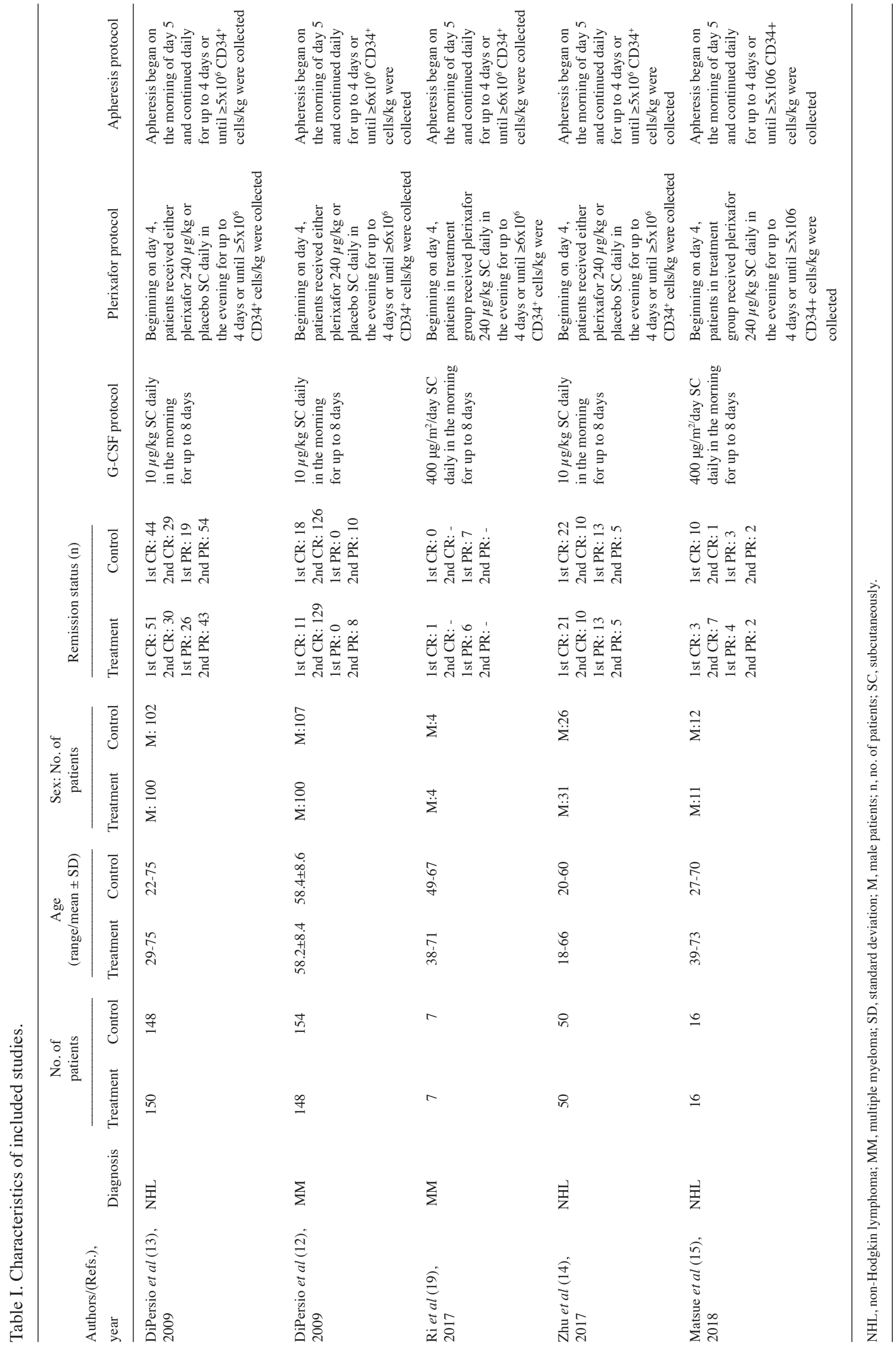


risk ratios (RR) with 95\% confidence intervals (CI) were calculated. The mean and standard deviation (SD) scores of the number of $\mathrm{CD} 34^{+}$cells collected were used for the meta-analysis.

\section{Results}

Search outcome. The search outcome of the review is presented in Fig. 1. A total of 195 articles were examined by their abstracts. In total, 186 studies were excluded due to non-relevance, leaving a total of 9 articles $(12-15,19-23)$. Four studies were excluded from the review, as 2 were non-randomized $(22,23), 1$ had no control group (20) and 1 used a retrospective control group (21). A total of 5 trials were included in this systematic review and meta-analysis $(12-15,19)$.

Characteristics of included studies and data analysis. Details of the included studies are presented in Table I. Three studies (12-14) were multi-center studies, while 2 were single-center trials $(15,19)$. Three studies $(13-15)$ were carried out on NHL, while 2 trials $(12,19)$ were on patients with MM. Two trials [1 on NHL (15) and 1 on MM (19)] did not administer any placebo to the control group. The G-CSF protocol was standard across the studies, which consisted of subcutaneous (SC) injections in the morning for 8 days. Similarly, plerixafor was injected by SC injection in the evening, beginning on day 4 in all studies for up to 4 days and apheresis was carried out from the morning of day 5 and continued daily for up to 4 days or till the targeted HSC collection was reached. In the studies on NHL, the optimal HSC collection was $\geq 5 \times 10^{6} \mathrm{CD} 34^{+}$cells $/ \mathrm{kg}$, while in the MM studies, it was $\geq 6 \times 10^{6} \mathrm{CD} 34^{+}$cells $/ \mathrm{kg}$.

Data on successful optimal HSC mobilization i.e., the collection of $\geq 5 \times 10^{6} \mathrm{CD} 34^{+}$cells $/ \mathrm{kg}$ or $\geq 6 \times 10^{6} \mathrm{CD} 34^{+}$cells $/ \mathrm{kg}$ in $\leq 4$ apheresis days was available from 4 included studies (Table II). From the pooling of the data of 364 patients in the treatment group and 368 patients in the control group, it was found that patients randomized to plerixafor had better successful HSC mobilization than those in the control group ( $R R=2.59,95 \%$ CI: 1.40 to 4.81; $P<0.0001$; Fig. 2). There was significant heterogeneity $\left(\mathrm{I}^{2}=86 \%\right)$, which could be attributed to different underlying conditions or a different targeted stem cell number. Subgroup analysis based on diagnosis demonstrated a statistically significant improvement in optimal HSC collection in both the NHL and MM subgroup. Data on successful minimal HSC mobilization i.e., the collection of $\geq 2 \times 10^{6} \mathrm{CD} 34^{+}$cells $/ \mathrm{kg}$ in $\leq 4$ apheresis days of 371 patients in the treatment group and 375 patients in the control group was also pooled for analysis. The results indicated that patients in the plerixafor group had better minimal HSC mobilization than those in the control group (RR=1.46, 95\% CI: 1.01 to 2.12; $\mathrm{P}=0.04 ; \mathrm{I}^{2}=94 \%$; Fig. 3). Subgroup analysis based on diagnosis indicated a statistically significant difference in both the NHL and MM subgroups.

The number of days required to reach optimal $\left(\geq 5 / 6 \times 10^{6}\right.$ $\mathrm{CD} 34^{+}$cells $\left./ \mathrm{kg}\right)$ or minimal $\left(\geq 2 \times 10^{6} \mathrm{CD} 34^{+}\right.$cells $\left./ \mathrm{kg}\right) \mathrm{HSC}$ mobilization reported by the studies is presented in Table II. Since only median values were available, data could not be pooled for a quantitative analysis. The qualitative assessment of results from all 5 studies indicated that the addition of plerixafor significantly reduced the number of days required for the collection of optimal HSCs. Similarly, $4(13,14,15,19)$ of the 5 included trials, which studied median time (days) required

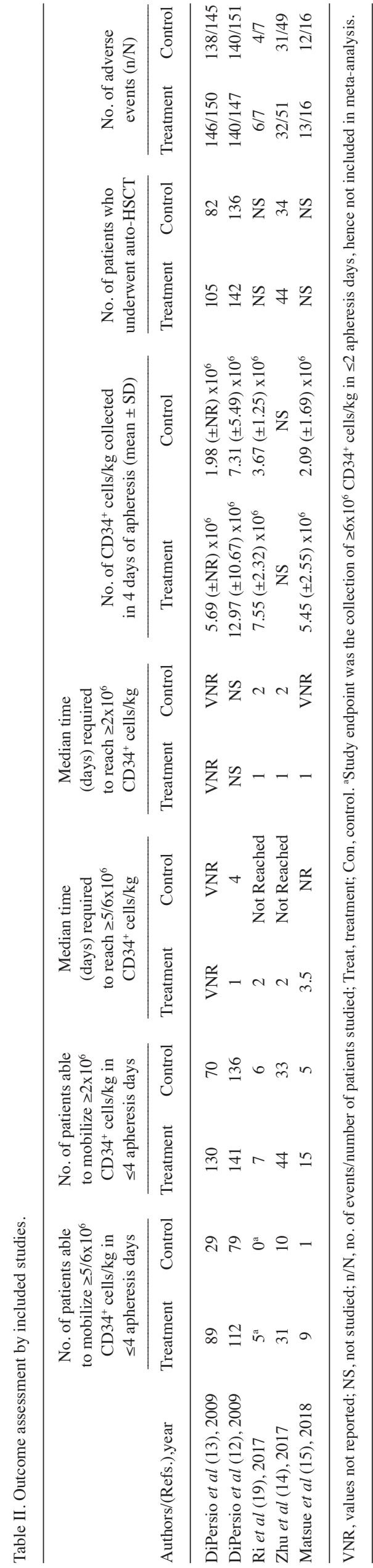


Control Plerixafor Risk Ratio

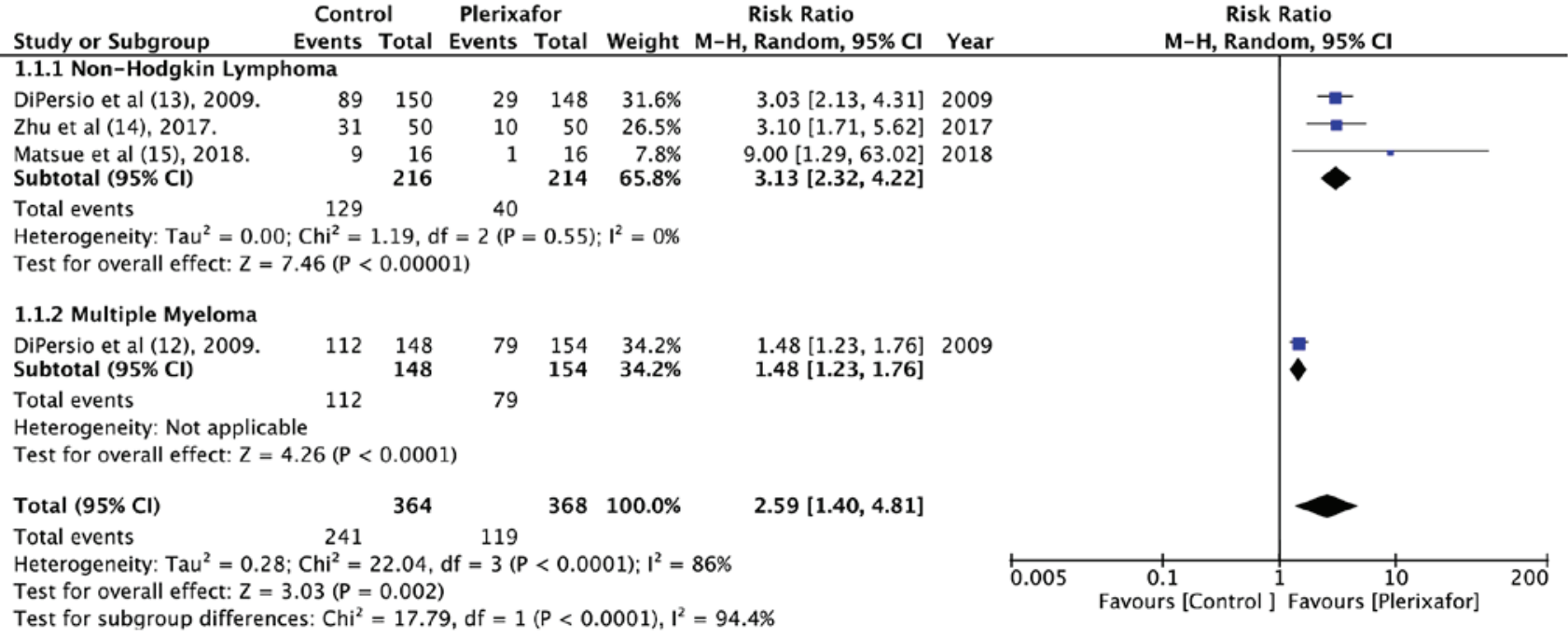

Figure 2. Forrest plot of non-Hodgkin lymphoma and multiple myeloma for the mobilization of optimal hematopoietic stem cells in 4 or less apheresis days.

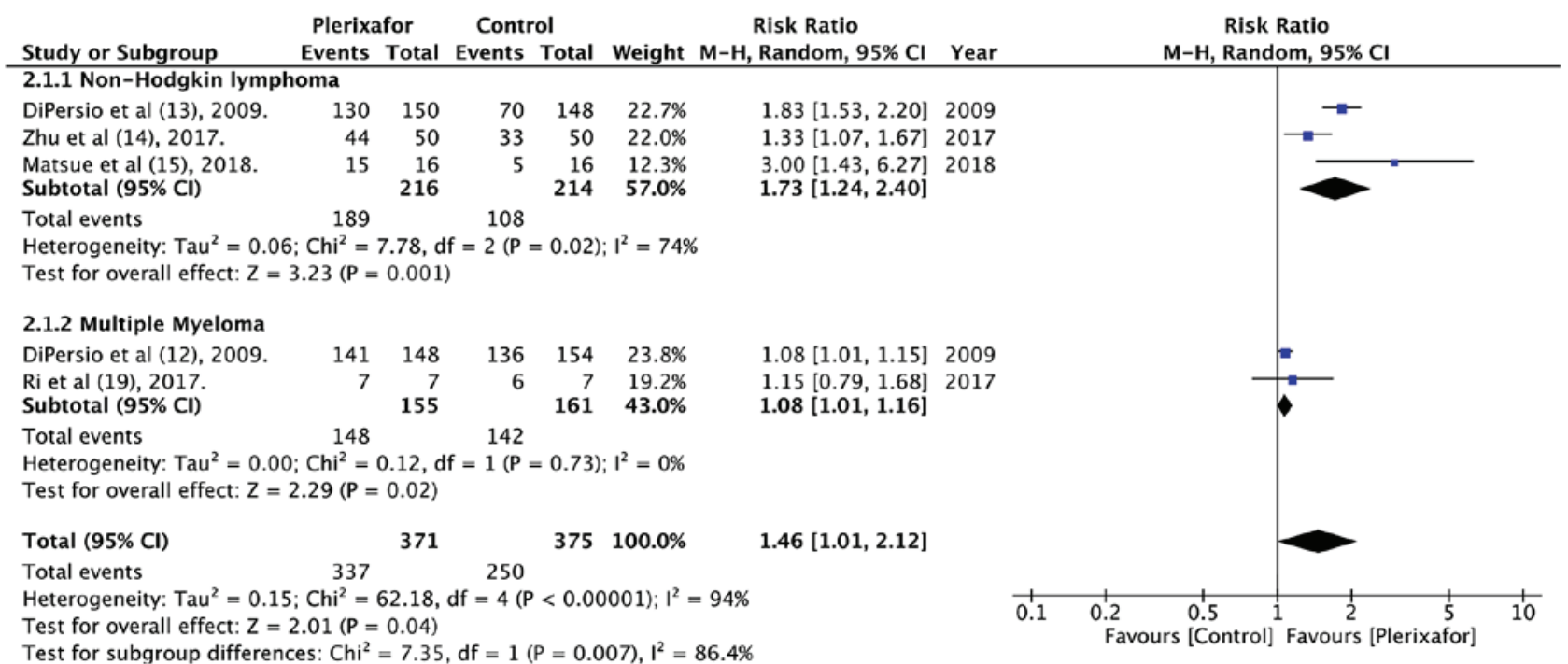

Figure 3. Forrest plot of non-Hodgkin lymphoma and multiple myeloma for the mobilization of minimal hematopoietic stem cells in 4 or less apheresis days.

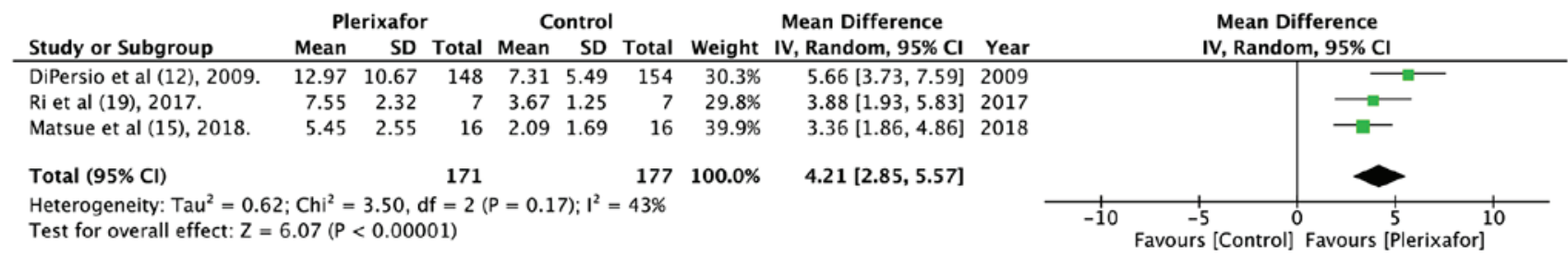

Figure 4. Forrest plot of mean total number of CD34+ cells collected in up to 4 apheresis days.

to reach $\geq 2 \times 10^{6} \mathrm{CD} 34^{+}$cells $/ \mathrm{kg}$, concluded that the number of days required for HSC mobilization to be less with plerixafor.

The mean total number of $\mathrm{CD} 34^{+}$cells collected in up to 4 apheresis days was studied by 4 trials $(12,13,15,19)$ (Table II). The data pooled from 3 studies $(12,15,19)$ indicated that the addition of plerixafor significantly increased the total collection of $\mathrm{CD}_{34}{ }^{+}$cells (random: $\mathrm{MD}=4.21 ; 95 \% \mathrm{CI}: 2.85$ to $5.57 ; \mathrm{P}<0.00001$; $\mathrm{I}^{2}=43 \%$; Fig. 4). In addition, a significantly greater number of patients randomized to plerixafor eventually underwent HSCT ( $R R=1.19,95 \%$ CI: 1.02 to $1.39 ; \mathrm{P}=0.03 ; \mathrm{I}^{2}=70 \%$; Fig. 5).
The numbers of patients experiencing at least 1 or more treatment related adverse events in both groups were pooled. The meta-analysis of 371 patients in the plerixafor group and 368 patients in the control group indicated no significant increase in adverse events with the addition of plerixafor $(\mathrm{R} R=1.03$, 95\% CI: 0.99 to $1.06 ; \mathrm{P}=0.16 ; \mathrm{I}^{2}=0 \%$; Fig. 6 ).

Quality of included studies. The risk of bias summary of the included studies is presented in Fig. 7. The randomization method was not described in 2 studies $(12,13)$ and 2 studies were not 


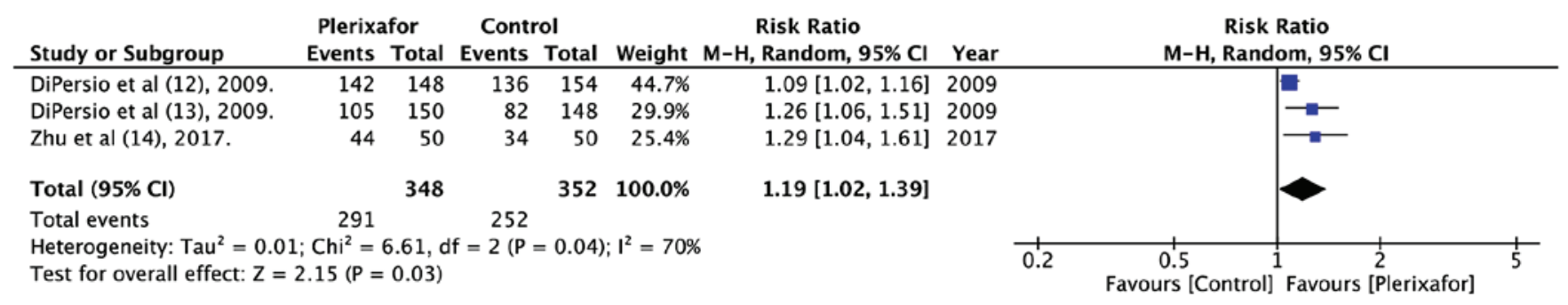

Figure 5. Forrest plot of the number of patients undergoing transplantation.

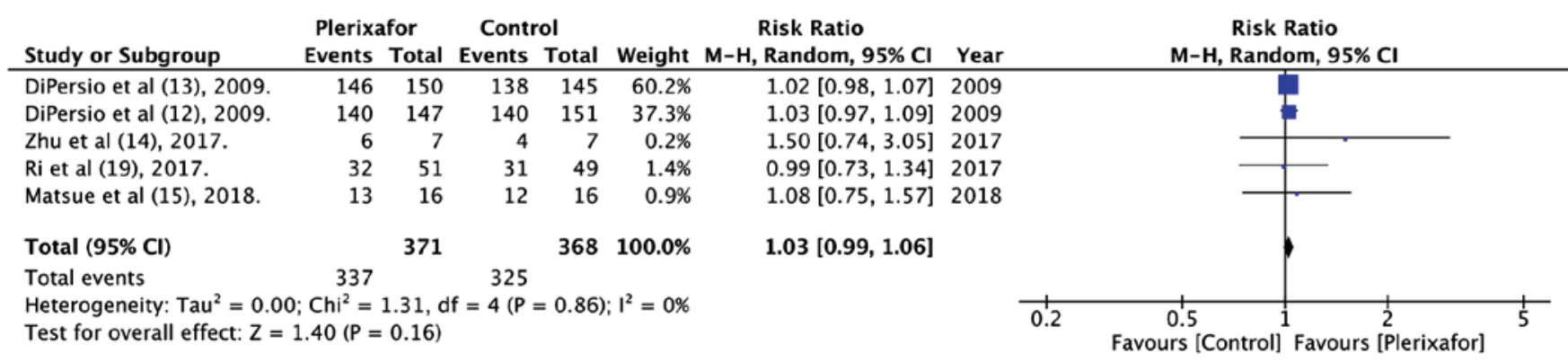

Figure 6. Forrest plot of adverse events.

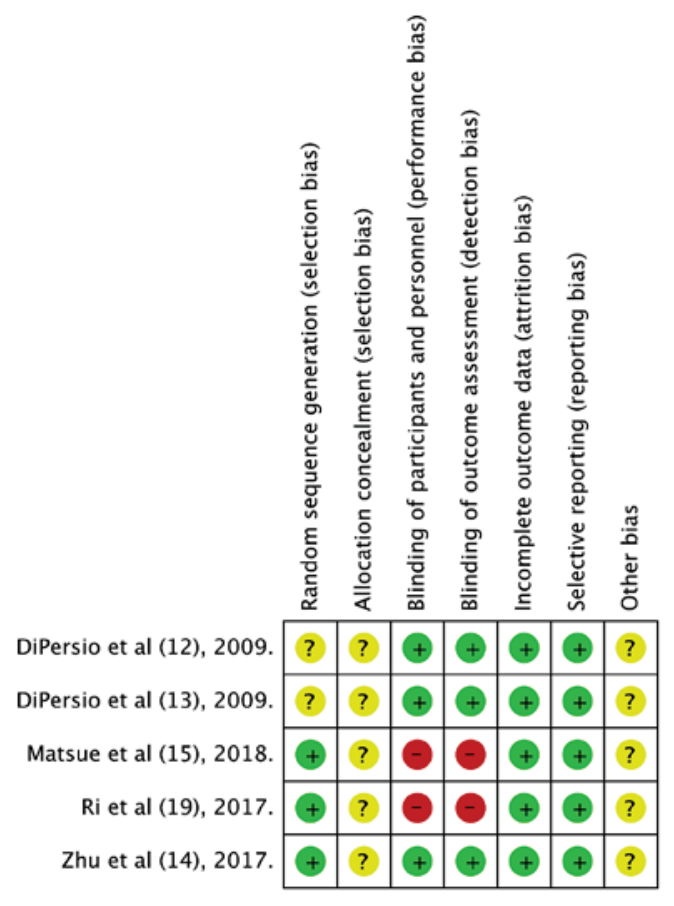

Figure 7. Risk of bias summary.

double blind $(15,19)$. Since all studies had financial support from pharmaceutical companies, they were marked with 'unclear risk' for other sources of bias. The overall quality of the studies was rated 'high' for 3 trials (12-14) and 'medium' for 2 trials $(15,19)$.

\section{Discussion}

In 2003, AMD3100, as plerixafor was formerly known, was studied by Liles et al (24) in healthy volunteers as a potential HSC mobilizer. The authors reported rapid generalized leukocytosis and an increase in the number of $\mathrm{CD} 34^{+}$cells in peripheral blood with a single dose of the drug. Later, in their study, serial administration of the drug at $80 \mu \mathrm{g} / \mathrm{kg} /$ day for 3 days resulted in a consistent, reversible increase in the number of $\mathrm{CD}_{3} 4^{+}$cells in peripheral blood with minimal toxicity. Their findings suggested the potential clinical application of plerixafor for HSCT. Their results were soon confirmed in patients with NHL and MM, where a significant increase in the CD34+ counts was noted (25). Phase 2 trials later established the superiority of plerixafor + G-CSF as compared to G-CSF alone for autologous HSC mobilization (26). Superior evidence in the form of RCTs by DiPersio et al $(12,13)$ paved the way for the approval of plerixafor by FDA in December, 2008 (27). The drug was ratified for use in patients with NHL and MM for the mobilization of HSCs for autologous transplantation. Since then, a number of studies have evaluated the role of plerixafor in patients with NHL and MM. Single arm prospective trials or retrospective studies form the bulk of the research conducted (28-30). The results of our systematic review indicated that $5 \mathrm{RCTs}$ evaluating the role of additional plerixafor to G-CSF have been published to date. Three of these were conducted on NHL (13-15) and 2 on patients with MM $(12,19)$. The study end-points were more or less similar across trials which enabled the pooling of the data for the purposes of our meta-analysis.

The minimum number of $\mathrm{CD} 34^{+}$cells likely to result in successful engraftment is generally considered to be $\geq 2 \times 10^{6}$ cells $/ \mathrm{kg}$, whereas the 'optimal' number of HSCs for transplantation is $4-6 \times 10^{6} \mathrm{CD} 34^{+}$cells $/ \mathrm{kg}$ (31). It has been found that the re-infusion of higher number of $\mathrm{CD} 34^{+}$cells is associated with earlier engraftment following transplantation, with better disease-free and overall survival than lower cell doses (32). As a result, many transplant centers strive to harvest the optimal number of HSCs rather than the minimal dose. The primary efficacy end-point in the majority of the included trials of this review was the collection of optimal HSCs in 4 or less apheresis days. The results of our meta-analysis revealed that patients receiving additional plerixafor were 2.59-fold more likely to achieve optimal HSC collection in 4 or less apheresis 
days. Similarly, patients in the plerixafor group were 1.46-fold more likely to mobilize minimal HSCs ( $\geq 2 \times 10^{6}$ cells $/ \mathrm{kg}$ in 4 or less apheresis days) as compared to those receiving G-CSF only. There was slight variation in the primary efficacy end-point in NHL and MM studies, with NHL studies reporting the mobilization of $\geq 5 \times 10^{6}$ cells $/ \mathrm{kg}$, while MM studies reporting the mobilization of $\geq 6 \times 10^{6}$ cells $/ \mathrm{kg}$ as the optimal number of HSCs for harvest. A higher primary endpoint is set for the collection of HSCs in patients with MM as they frequently require a second transplantation. A subgroup analysis was therefore carried out for NHL and MM, which demonstrated the effectiveness of plerixafor in both conditions. An important aspect to note is that only one study (12) was available evaluating the collection of optimal HSCs in 4 or less apheresis days for MM. The study by Ri et al (19) reported the collection of $\geq 6 \times 10^{6}$ cells $/ \mathrm{kg}$ in 2 or less apheresis days and was not pooled with the other study of DiPersio et al (12) for this variable.

In addition to the optimal collection of HSCs, another critical goal of stem cell mobilization is to collect cells in minimum number of days so as to reduce treatment stress and financial burden of the patient and also ensure optimal utilization of medical resources. Despite the fact that pooled analysis was not possible for the number of days needed for HSC mobilization with or without plerixafor, all studies included in this review reported the rapid mobilization with the drug. The median number of days for both optimal and minimal HSC mobilization was less with the addition of plerixafor. The more rapid collection of HSCs may lead to better patient compliance, reduce apheresis-associated risks and may shorten the interval between mobilization and transplant (15). The superior efficacy of plerixafor $+\mathrm{G}-\mathrm{CSF}$ was also observed in the total number of CD34+ cells collected and the number of patients who eventually underwent HSCT.

The safety profile of plerixafor was tested in all included studies. Based on our analysis and the investigation of individual trials, plerixafor is generally well-tolerated and there is no significant increase in treatment-related adverse events with the addition of the drug. In both the trials of DiPersio et al $(12,13)$, the majority of adverse events were gastrointestinal (GI) disorders or injection site reactions. Ri et al (19) reported increased headaches, diarrhea and back pain with the addition of plerixafor. Zhu et al (14) and Matsue et al (15) reported GI-related disorders and headaches to be more common in the plerixafor arm than the control arm. All adverse events reported were mild to moderate and there were no treatment-related deaths reported in any of the included studies.

As plerixafor tends to mobilize relatively different cell populations as compared to other methods of mobilizing CD $34^{+}$cells, post-transplant outcomes, such as hematopoietic and immune recovery and progression-free survival (PFS) are important variables of concern to clinicians (2). In total, 2 of the 5 included trials reported that engraftment and short-term outcomes at 12 months were similar with plerixafor + G-CSF and plerixafor + placebo. Importantly, the long-term results of these 2 studies have been published recently (33). The results indicated that the probability of overall survival and PFS evaluated over a period of 5 years did not differ significantly in patients with NHL or MM treated with plerixafor or the placebo. There is however, a need for more such long-term studies in order to validate the safety and efficacy of plerixafor for long-term PFS.
Some limitations of our review and meta-analysis need to be elaborated. Firstly, the paucity of RCTs limited the number of studies for inclusion in our review. Secondly, not all trials included were high quality studies. In total, 2 of the 5 included studies were sored as 'medium quality' based on the quality assessment tool. Thirdly, data on engraftment, long-term overall survival and PFS were not available from all included studies. Fourthly, as with any meta-analysis, heterogeneity as measured with $\mathrm{I}^{2}$ statistic was significant in all our investigations. The time period, locations and samples of individual trials are quite variable across studies, but are usually balanced between the two arms of the meta-analysis. Nevertheless, our systematic review and meta-analysis is a significant update from the last review published on the subject by Hartmann et al in 2015 (11). Data from a 3 additional trials were available and added for quantitative analysis. The results of this study indicate that addition of plerixafor to G-CSF leads to increased HSC collection in a shorter period of time with no concomitant increase in adverse events. Further RCTs with a larger sample size evaluating short-term efficacy, as well as long-term survival would help to further strengthen evidence on this subject.

\section{Acknowledgements}

Not applicable.

\section{Funding}

This study was supported by the National Natural Science Funding Project (grant no. 8187014).

\section{Availability of data and materials}

The datasets used and/or analyzed during the current study are available from the corresponding author on reasonable request.

\section{Authors' contributions}

XY conceived and designed the study. MW, FY and ZW collected the data and performed the literature search. All authors were involved in writing the manuscript. All authors have read and approved the final manuscript.

\section{Ethics approval and consent to participate}

Not applicable.

\section{Patient consent for publication}

Not applicable.

\section{Competing interests}

The authors declare that they have no competing interests.

\section{References}

1. Hoggatt J, Speth JM and Pelus LM: Concise review: Sowing the seeds of a fruitful harvest: hematopoietic stem cell mobilization. Stem Cells 31: 2599-2606, 2013. 
2. Jantunen E, Varmavuo V and Valtola J: Plerixafor injection: A hematopoietic stem cell mobilizer in non-Hodgkin lymphoma and multiple myeloma. Expert Rev Hematol 9: 723-732, 2016.

3. Duong HK, Savani BN, Copelan E, Devine S, Costa LJ, Wingard JR, Shaughnessy P, Majhail N,Perales MA, Cutler CS, et al: Peripheral blood progenitor cell mobilization for autologous and allogeneic hematopoietic cell transplantation: Guidelines from the American Society for Blood and Marrow Transplantation. Biol Blood Marrow Transplant 20: 1262-1273, 2014.

4. Hosing C,Saliba RM, Ahlawat S, Körbling M,Kebriaei P,Alousi A, De Lima M, Okoroji JG, McMannis J, Qazilbash M, et al: Poor hematopoietic stem cell mobilizers: A single institution study of incidence and risk factors in patients with recurrent or relapsed lymphoma. Am J Hematol 84: 335-337, 2009.

5. Pusic I, Jiang SY, Landua S, Uy GL, Rettig MP, Cashen AF, Westervelt P, Vij R, Abboud CN, Stockerl-Goldstein KE, et al: Impact of mobilization and remobilization strategies on achieving sufficient stem cell yields for autologous transplantation. Biol Blood Marrow Transplant 14: 1045-1056, 2008.

6. Kessans MR, Gatesman ML and Kockler DR: Plerixafor: A peripheral blood stem cell mobilizer. Pharmacotherapy 30: 485-492, 2010.

7. Hübel K, Liles WC, Broxmeyer HE, Rodger E, Wood B, Cooper S, Hangoc G, Macfarland R, Bridger GJ, Henson GW, et al: Leukocytosis and Mobilization of CD34+ Hematopoietic Progenitor Cells by AMD3100, a CXCR4 Antagonist. Support Cancer Ther 1: 165-172, 2004

8. Russell N, Douglas K, Ho AD, Mohty M, Carlson K, Ossenkoppele GJ, Milone G, Pareja MO, Shaheen D, Willemsen A, et al: Plerixafor and granulocyte colony-stimulating factor for first-line steady-state autologous peripheral blood stem cell mobilization in lymphoma and multiple myeloma: Results of the prospective PREDICT trial. Haematologica 98: 172-178, 2013

9. Bilgin YM and de Greef GE: Plerixafor for stem cell mobilization: The current status. Curr Opin Hematol 23: 67-71, 2016.

10. De Clercq E: Mozobil ${ }^{\circledR}$ (Plerixafor, AMD3100), 10 years after its approval by the US Food and Drug Administration. Antivir Chem Chemother 27: 2040206619829382, 2019.

11. Hartmann T, Hübel K, Monsef I, Engert A and Skoetz N: Additional plerixafor to granulocyte colony-stimulating factors for haematopoietic stem cell mobilisation for autologous transplantation in people with malignant lymphoma or multiple myeloma. Cochrane Database Syst Rev 20: CD010615, 2015.

12. DiPersio JF, Stadtmauer EA, Nademanee A, Micallef IN, Stiff PJ, Kaufman JL, Maziarz RT, Hosing C, Früehauf S, Horwitz M, et al; 3102 Investigators: Plerixafor and G-CSF versus placebo and G-CSF to mobilize hematopoietic stem cells for autologous stem cell transplantation in patients with multiple myeloma. Blood 113: 5720-5726, 2009.

13. DiPersio JF, Micallef IN, Stiff PJ, Bolwell BJ, Maziarz RT, Jacobsen E, Nademanee A, McCarty J, Bridger G and Calandra G; 3101 Investigators: Phase III prospective randomized double-blind placebo-controlled trial of plerixafor plus granulocyte colony-stimulating factor compared with placebo plus granulocyte colony-stimulating factor for autologous stem-cell mobilization and transplantation for patients with non-Hodgkin's lymphoma. J Clin Oncol 27: 4767-4773, 2009.

14. Zhu J, Huang H, Chen H, Zhang X, Li Z, Wu D, Zhou D, Song Y, $\mathrm{Hu}$ Y, Liang Y, et al: Plerixafor and granulocyte-colony-stimulating factor for mobilization of hematopoietic stem cells for autologous transplantation in Chinese patients with non-Hodgkin's lymphoma: A randomized Phase 3 study. Transfusion 58: 81-87, 2018.

15. Matsue K, Kumagai K, Sugiura I, Ishikawa T, Igarashi T, Sato T, Uchiyama M, Miyamoto T, Ono T, Ueda Y, et al: Plerixafor for mobilization and collection of haematopoietic stem cells for autologous transplantation in Japanese patients with non-Hodgkin lymphoma: A randomized phase 2 study. Int $\mathrm{J}$ Hematol 108: 524-534, 2018.

16. Moher D, Liberati A, Tetzlaff J and Altman DG; PRISMA Group: Preferred reporting items for systematic reviews and meta-analyses: The PRISMA statement. PLoS Med 6: e1000097, 2009.

17. Higgins J and Green S (eds): Cochrane Handbook for Systemic Reviews of Interventions. Version 5. The Cochrane Collaboration, 2011.

18. Higgins J, Altman D and Sterne J; Cochrane Statistical Methods Group and the Cochrane Bias Methods Group (eds): Chapter 8: assessing risk of bias in included studies. In: Cochrane Handbook for Systemic Reviews of Interventions, Version 5. The Cochrane Collaboration, 2011.
19. Ri M, Matsue K, Sunami K, Shimazaki C, Hayashi A, Sunaga Y, Sasaki T and Suzuki K: Efficacy and safety of plerixafor for the mobilization/collection of peripheral hematopoietic stem cells for autologous transplantation in Japanese patients with multiple myeloma. Int J Hematol 106: 562-572, 2017.

20. Dugan MJ, Maziarz RT, Bensinger WI, Nademanee A, Liesveld J, Badel K, Dehner C, Gibney C, Bridger G and Calandra G: Safety and preliminary efficacy of plerixafor (Mozobil) in combination with chemotherapy and G-CSF: An open-label, multicenter, exploratory trial in patients with multiple myeloma and non-Hodgkin's lymphoma undergoing stem cell mobilization. Bone Marrow Transplant 45: 39-47, 2010.

21. Martin AP, Richards S, Haycox A, Houten R, McLeod C, Braithwaite B, Clark JO, Bell J and Clark RE: Evaluating the use of plerixafor in stem cell mobilisation - an economic analysis of the PHANTASTIC trial. J Clin Apher 31: 434-442, 2016.

22. Haverkos BM, Huang Y, Elder P, O'Donnell L, Scholl D, Whittaker B, Vasu S, Penza S, Andritsos LA, Devine SM, et al: A single center's experience using four different front line mobilization strategies in lymphoma patients planned to undergo autologous hematopoietic cell transplantation. Bone Marrow Transplant 52: 561-566, 2017.

23. Partanen A, Valtola J, Ropponen A, Vasala K, Penttilä K, Ågren L, Pyörälä M, Nousiainen T, Selander T, Mäntymaa P, et al: Preemptive plerixafor injection added to pegfilgrastim after chemotherapy in non-Hodgkin lymphoma patients mobilizing poorly. Ann Hematol 96: 1897-1906, 2017.

24. Liles WC, Broxmeyer HE, Rodger E, Wood B, Hübel K, Cooper S, Hangoc G, Bridger GJ, Henson GW, Calandra G, et al: Mobilization of hematopoietic progenitor cells in healthy volunteers by AMD3100, a CXCR4 antagonist. Blood 102: 2728-2730, 2003.

25. Devine SM, Flomenberg N, Vesole DH, Liesveld J, Weisdorf D, Badel K, Calandra G and DiPersio JF: Rapid mobilization of CD34+ cells following administration of the CXCR4 antagonist AMD3100 to patients with multiple myeloma and non-Hodgkin's lymphoma. J Clin Oncol 22: 1095-1102, 2004.

26. Flomenberg N, Devine SM, Dipersio JF, Liesveld JL, McCarty JM, Rowley SD, Vesole DH, Badel K and Calandra G: The use of AMD3100 plus G-CSF for autologous hematopoietic progenitor cell mobilization is superior to G-CSF alone. Blood 106: 1867-1874, 2005.

27. Brave M, Farrell A, Ching Lin S, Ocheltree T, Pope Miksinski S, Lee SL, Saber H, Fourie J, Tornoe C, Booth B, et al: FDA review summary: Mozobil in combination with granulocyte colony-stimulating factor to mobilize hematopoietic stem cells to the peripheral blood for collection and subsequent autologous transplantation. Oncology 78: 282-288, 2010.

28. Yuan S, Palmer JM, Tsai N-C, Dagis A, Nademanee A and Wang S: Engraftment and outcomes following autologous stem cell transplantation in Hodgkin lymphoma patients mobilized with plerixafor. Hematol Oncol 35: 281-287, 2017.

29. Milone G, Martino M, Leotta S, Spadaro A, Zammit V, Cupri A, Avola G, Camuglia MG, Di Marco A, Scalzulli P, et al: Cost-effectiveness of on-demand plerixafor added to chemotherapy and granulocyte-colony stimulating factor for peripheral blood stem cell mobilization in multiple myeloma. Leuk Lymphoma 59: 42-48, 2018.

30. Mohty M, Azar N, Chabannon C, Le Gouill S, Karlin L, Farina L, Milkovich G, Ostermann H, Glaß B, Noppeney R, et al: Plerixafor in poor mobilizers with non-Hodgkin's lymphoma: A multi-center time-motion analysis. Bone Marrow Transplant 53: 246-254, 2018.

31. Lemoli RM: New strategies for stem cell mobilization. Mediterr J Hematol Infect Dis 4: e2012066, 2012.

32. Shpall EJ, Champlin R and Glaspy JA: Effect of CD34+ peripheral blood progenitor cell dose on hematopoietic recovery. Biol Blood Marrow Transplant 4: 84-92, 1998.

33. Micallef IN, Stiff PJ, Nademanee AP, Maziarz RT, Horwitz ME, Stadtmauer EA, Kaufman JL, McCarty JM, Vargo R, Cheverton PD, et al: Plerixafor Plus Granulocyte Colony-Stimulating Factor for Patients with Non-Hodgkin Lymphoma and Multiple Myeloma: Long-Term Follow-Up Report. Biol Blood Marrow Transplant 24: 1187-1195, 2018.

This work is licensed under a Creative Commons Attribution-NonCommercial-NoDerivatives 4.0 International (CC BY-NC-ND 4.0) License. 